Commentary

\title{
Conflicting perceptions of the status of field biology and identification skills in UK education
}

\author{
Raymond Goulder and Graham W. Scott
}

School of Biological, Biomedical and Environmental Sciences, University of Hull, Hull HU6 7RX, UK

There is an enormous degree of engagement between people and the outdoors in the UK; $58 \%$ of the adult population of England, about 24 million people, make at least one visit a week to parks, urban greenspaces, the countryside or other outdoor destinations. Having nearby greenspace is important to $52 \%$ of adults and $37 \%$ of them claim to watch wildlife while outdoors (Natural England 2015a). Children, usually encouraged by adults, also make many visits to the 'natural' environment; $70 \%$ of children in England, about 7 million, visit natural environments at least once a week (Natural England 2015b). There is, nevertheless, an ongoing thread of opinion and research that suggests that engagement with and knowledge and understanding of the natural environment and knowledge of plants and animals may be decreasing in affluent consumer societies. Thus Pergams and Zaradic (2008) described a shift away from visits to the outdoors and nature-based recreation in the US and Japan. There is also evidence of widespread decrease in support for natural history in developed economies despite its huge importance to society (Tewksbury et al. 2015).

There is a strand of opinion to the effect that decline in the role of natural history in the UK is associated with serious decline in learning and teaching about field biology skills in schools and universities. It is believed that this decline is especially shown by those skills that are needed to identify plants and animals and that are essential for an appreciation of natural history and for meaningful ecological study. For example Bilton (2014) expressed the view that today's first year biology undergraduates typically cannot identify common plants and animals unlike students of 30 years ago. Leather and Quicke $(2009,2010)$ considered that students in universities and schools learn little or nothing about identification skills and that this is associated with an abysmal lack of natural history knowledge in schools, universities and the general populace. Ashton et al. (2015) strongly expressed this point of view. They believe that the decline in field biology skills in UK higher education has reached crisis point; for this they blame the rise in molecular biology, loss of field-competent teachers, and children's loss of interest in the outdoors. Above all they blame educationalists! Their view is that the design of university curricula has been adversely influenced by the application of the system that classifies levels of learning known as Bloom's taxonomy (e.g. Atherton 2013). They believe that the designers of biology curricula in universities have ruthlessly insisted that field identification skills belong within the lowest stratum of the cognitive domain and are too simple to be appropriate to a university education. Hence their omission from today's degree programmes. This point of view is roundly contradicted by the work of Maw, Mauchline and Park (2011) who found that when fieldwork teachers from 27 UK universities were asked about key skills acquired through fieldwork they placed identification/classification as their highest priority; moreover the prevailing response of fieldwork teachers was to the effect that fieldwork was central to their pedagogic approach (Mauchline, Peacock and Park 2013). Ashton et al. (2015) are also critical of schools; they believe that from the nature table of primary school onwards identification skills are not taken 
seriously and this dismissive message is reinforced throughout later schooling and brought by pupils to university.

In an historical context this strand of negative opinion has support from objective analysis. Smith (2004) reviewed the status of biological fieldwork in UK undergraduate programmes and found that an overall increase in student numbers had apparently not been matched by a parallel increase in fieldwork. Forces tending to restrict fieldwork included: shortage of teaching staff with field experience; lack of funding from universities and the need for students to contribute to costs; safety issues and a perceived climate of litigation; loss of students' earnings during their participation in vacation field courses. Ambivalence towards fieldwork shown by the QAA Benchmark Statement for Biosciences was also seen as a negative factor. There is also evidence for decline in schools. Decrease in school fieldwork in England and Wales following the introduction of a statutory national curriculum in 1988 was charted by Fisher (2001). Decrease was also demonstrated by the review of age 14-19 fieldwork in schools by Barker, Slingsby and Tilling (2002). These authors emphasized that relatively little objective evidence was available and that many accounts of the state of fieldwork are based on personal evidence and anecdote, nevertheless they concluded that there had been a real decline in fieldwork in UK secondary schools. The reasons suggested for this decline included: change in the 16-19 curriculum and the loss of flexibility associated with a modular structure; change in practical assessment that had squeezed out fieldwork assessments; change in school management with a move to in-school budgeting and the loss of LEA subsidy of field courses; fear of accidents and the likelihood that individual teachers would be regarded as personally responsible; fewer new teachers with fieldwork experience; the relatively low profile of field biology in contrast to the 'new' molecular biology.

So far much of the above is decidedly discouraging. However, some of the writing that we have cited reads rather like hyperbole, intended to make a point but perhaps tending to stray beyond constraints imposed by evidence. We now consider some specific examples of negativity that have been expressed about the state of fieldwork, identification skills and appreciation of natural history to see how these align with our experience and observation.

That today's biology students lack identification skills. Bilton (2014) took the view that 30 years ago most biology undergraduates would have possessed the skills needed to identify common plants and animals but that this is not so nowadays. In this vein Leather \& Quicke (2009) gave the very precise example that 20 years ago if first-year students were sent out to collect leaves from common trees and identify them they could have successfully completed the task; today only final-year students would be capable of the task, and then only a minority of them. Perhaps, however, a distinction needs to be made between having prior knowledge of the names of plants and having the ability to identify unknown plants. It may be that students of 20 or 30 years ago held more plant names in their head when they arrived at university but it is, we believe, the ability to identify hitherto unknown plants that is more important. By chance the identification of trees is exactly the task that we have in recent years set students following a pre-Certificate year (approximately A-level equivalent) at Hull University; we found that these students were able to identify trees. Groups of students collected foliage samples from trees in and around extensive plantation forest in North Yorkshire and then worked in a forest classroom to identify and draw the samples. There was help from tutors and extensive use was made of identification keys. By the end of the day one class of 52 students had between them identified 18 coniferous trees and 27 
broad-leaved trees and shrubs (Goulder and Scott 2009). The identifications were largely correct; few trees were obviously misidentified in the drawings and written work that were handed in.

That field biology and identification skills are omitted from today's HE biology programmes. Ashton et al. (2015), we suppose tongue-in-cheek, asserted that each year there are fewer than ten UK graduates who are sufficiently proficient in field identification skills to be employable. They were quickly countered by Shreeve and Riddoch (2015) who pointed out that more than ten appropriately qualified students graduate each year from Oxford Brookes University alone. In reality it is obvious that field and identification skills are taught in UK universities; our brief search of somewhat randomly selected UK university websites yielded many module specifications for field based biology modules, at various levels of study, that referred specifically to the identification of plants or animals and half of these referred to the use of keys for identification (Goulder and Scott 2015).

That it is predominantly older people that are enthusiastic about field biology and identifying plants and animals. Leather and Quicke (2010) drew attention to the recent greater availability and quality of field guides yet they suggest that if, for example, field meetings of natural history societies are attended where these books are used, the participants will largely be elderly. We suggest that the age-structure of users of field guides and participants in field work depends upon context. The class described above identifying trees (Goulder and Scott 2009) were mostly 18-20 year olds, whereas a field class on identification of aquatic plants in canals for CIEEM led by one of us (RG) in summer 2015 was attended by young and mid-life environmental professionals; a similar excursion for the East Yorkshire Botany Club had elderly participants including at least one nonagenarian. Furthermore, one-day plant identification workshops aimed at beginners and held by the BSBI in 2015 attracted around 150 people (Anstey 2015); participants included many students and consultancy workers and seem not to have been predominantly elderly.

That field and identification skills are disregarded in schools from the primary level onwards. It was suggested by Ashton et al. (2015) that there is a lost generation of field biologists and that serious disregard of identification skills has permeated down to primary schools. They are dismissive of the nature table, although there is support for nature tables from Bilton (2014) and for 'mini-beasts' and wild life gardens from Leather and Quicke (2009).

Unfortunately it is true that there are constraints that tend to restrict field and natural history teaching in primary schools (Scott et al. 2015). Some are tangible (e.g. lack of equipment and field sites, cost, class size, limitations of timetable and curriculum) others are less so, most notably a lack of teacher confidence in an outdoor setting. Teachers fear loss of their expert status and loss of discipline but these fears can relatively easily be overcome. Scott, Boyd and Colquhoun (2013) showed that when teachers with little experience of field teaching took classes of primary school children into the field, and worked with them on producing photographic field guides to plants and/or animals, the children identified the animals/plants of the habitats they visited without the assistance of adult helpers through the use of the FSC illustrated identification charts, e.g. the charts for trees, grasses, woodland plants, common ferns (Field Studies Council 2015). One group of 26 children identified 12 trees in a wood adjacent to their school. The children enjoyed working in partnership with one another and their teachers and the fears of the teachers were not realized. 
The reviews of the state of biology fieldwork in UK schools and universities at the beginning of the $21^{\text {st }}$ century (Barker, Slingsby and Tilling 2002; Smith 2004) were not entirely pessimistic; rather they suggested ways forward that might lead to an increase in fieldwork. Whether their hopes have been realized has, perhaps, been revealed by later studies. In 2006 the National Foundation for Educational Research comprehensively surveyed the extent of learning outside the classroom in English schools (O'Donnell, Morris and Wilson 2006). This survey included all kinds of fieldwork as well as that in biology and it concluded that, although many commentators had argued that there was a decline in fieldwork, there was little evidence in support of decline. Schools and local authorities considered that provision had increased or remained largely the same over the previous five years. Field work by primary schools on school sites was commonly reported as increasing. Less encouraging, however, are the findings of a meta-study by Lock (2010) of publications between 1963 and 2009, although only three out of 13 of these reported surveys done after 2000, which addressed biology fieldwork provision for 16-19 year olds in UK schools and colleges. This study suggested that according to several criteria (time in the field, the number of teachers taking fieldwork, teacher perception of change and the amount of residential fieldwork) the extent of fieldwork had declined. Other criteria (the number and type of habitats visited) showed no clear evidence of change. The current status of fieldwork in UK universities, notwithstanding the negative comment that we have reported above, appears to be buoyant. Maw, Mauchline and Park (2011) surveyed academics from 27 institutions by questionnaire in 2010 and found no evidence of a decrease in biological fieldwork over the previous five years. Furthermore, when staff from 27 universities were interviewed by Skype or telephone in 2012 (Mauchline, Peacock and Park 2013) there was no evidence of decline in fieldwork over the previous five years; fieldwork was greatly valued and a future increase was predicted in some institutions. The funding of fieldwork in UK universities has been anomalous in that students have sometimes been charged for fieldwork costs whereas expensive consumables used in laboratory classes have been provided without extra charge. Mauchline, Peacock and Park (2013) suggested that the introduction of full-cost fees from 2012 has led to the deletion of extra charges for fieldwork; they suggest that this may boost fieldwork. Other suggested positive factors are that the promise of fieldwork enhances student recruitment, that fieldwork skills enhance employability and that students enjoy doing fieldwork. This is supported by our experience with students at Hull University; we found that they valued fieldwork because of its leading to outdoor career opportunities and they largely enjoyed the fieldwork experience (Scott et al 2012; Goulder, Scott and Scott 2013). All in all, although there is clearly much difference of opinion, we are unconvinced that biological fieldwork and identification skills are currently at significant risk in UK universities; we also believe that fieldwork in schools has the potential for a positive future.

\section{References}

Anstey, F. 2015. "Beginners' Workshops." BSBI News 130: 50-51.

Ashton, P., S. Taylor, P. Thomas, S. Townsend and J. Warren. 2015. "Save Field Biology Skills From Extinction." BBSI News 129: 6-7 (Reprinted from Times Higher Education 26th February 2015).

Atherton, J. S. 2013. "Learning and Teaching: Bloom's Taxonomy" http://www.learningandteaching.info/learning/bloomtax.htm. (Retrieved 17th October 2015). 
Barker, S., D. Slingsby. and S. Tilling. 2002. Teaching Biology Outside the Classroom: is it Heading for Extinction. A Report on Biology Fieldwork in the 14-19 Curriculum. Field Studies Council, Shrewsbury.

Bilton, D. T. 2014. "What's in a Name? What have Taxonomy and Systematics Ever Done for us?" Journal of Biological Education 48 (3): 116-118.

Field Studies Council 2015. Fold-out Identification Charts. www.field-studiescouncil.org/publications/fold-out-charts.aspx. (Retrieved 22 October 2015).

Fisher, J. A. 2001. "The Demise of Fieldwork as an Integral Part of Science Education in United Kingdom Schools: a Victim of Cultural Change and Political Pressure." Pedagogy, Culture and Society 9 (1): 75-96.

Goulder, R. and G. W. Scott. 2009. "Field Study of Plant Diversity: Extending the WholeClass Knowledge Base through Open-Ended Learning." Bioscience Education 14. www.bioscience.heacademy.ac.uk/journal/vol14/beej-14-1.pdf.

Goulder, R. and G. W. Scott. 2015. "Higher Education and the Future of Field Biology Skills: too much Gloom?" BSBI News 130; 23-25.

Goulder, R., G. W. Scott and L. J. Scott. 2013. "Students' Perception of Biology Fieldwork: the Example of Students Undertaking a Preliminary Year at a UK University." International Journal of Science Education 35 (8): 1385-1406.

Leather, S. R. and D. J. L. Quicke. 2009. "Where would Darwin have been without Taxonomy? Journal of Biological Education 43 (2): 51-52.

Leather, S. R. and D. J. L. Quicke. 2010. "Do Shifting Baselines in Natural History Knowledge Threaten the Environment?" Environmentalist 30 (1): 1-2.

Lock, R. 2010. "Biology Fieldwork in Schools and Colleges in the UK: an Analysis of Empirical Research from 1963 to 2009". Journal of Biological Education 44 (2) 58-64.

Mauchline, A. L., J. Peacock and J. R. Park. 2013. "The Future of Bioscience Fieldwork in UK Higher Education." Bioscience Education 21 (1): 7-19. DOI: 10.11120/beej.2013.00014.

Maw, S. J., A. L. Mauchline and J. R. Park. 2011. "Biological Fieldwork Provision in Higher Education." Bioscience Education 17. www.bioscience.heacademy.ac.uk/journal/vol17/beej-17-1.pdf.

Natural England. 2015a. Monitor of Engagement with the Natural Environment: the National Survey on People and the Natural Environment. Annual Report from the 2013-2014 Survey. http://publications. naturalengland.org.uk/publication/6579788732956672? category=470 18.

Natural England. 2015b. Monitor of Engagement with the Natural Environment: a Pilot for an Indicator of Visits to the Natural Environment by Children - Interim Findings from Year 1 (March 2013 to February 2014). Natural England Commissioned Report NECR166. http://publications.naturalengland.org.uk/publication/4781405798137856.

O'Donnell, L., M. Morris and R. Wilson. 2006. Education Outside the Classroom: an Assessment of Activity and Practice in Schools and Local Authorities. National Foundation for Educational Research, Research Report RR803.

Pergams, O. R. W. and P. A. Zaradic. 2008. "Evidence for a Fundamental and Pervasive Shift Away From Nature-Based Recreation”. PNAS 105 (7): 2295-2300.

Scott, G., M. Boyd and D. Colquhoun. 2013. "Changing Spaces, Changing Relationships: the Positive Impact of Learning Out of Doors". Australian Journal of Outdoor Education 17 (1): 47-53. 
Scott, G. W., M. Boyd, L. Scott and D. Colquhoun. 2015. "Barriers to Biological Fieldwork: What Really Prevents Teaching Out of Doors." Journal of Biological Education 49 (2): 165-178.

Scott, G. W., R. Goulder, P. Wheeler, L. J. Scott, M. L. Tobin and S. Marsham. 2012. "The Value of Fieldwork in Life and Environmental Sciences in the Context of Higher Education: a Case Study in Learning about Biodiversity." Journal of Science Education and Technology 21 (1):11-21

Shreeve, T. and B. Riddock. 2015. "Open Eyes to Field Skills." Times Higher Education, Letters, $20^{\text {th }}$ March.

Smith, D. 2004. "Issues and Trends in Higher Education Biology Fieldwork." Journal of Biological Education 39 (1): 6-10.

Tewksbury, J. J., J. G. T. Anderson, J. D. Bakker, T. J. Billo, P. W. Dunwiddie, M. J. Groom, S. E. Hampton, S. G. Herman, D. J. Levey, N. J. Machnicki, C Martínez Del Rio, M. E. Power, K. Rowell, A. K. Salomon, L. Stacey, S. C. Trombulak and T. A. Wheeler. 2015. "Natural History's Place in Science and Society." Bioscience 64 (4): 300-310. 